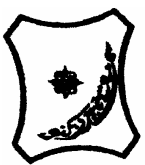

\title{
STUDIES OF MN (II) AND NI (II) COMPLEXES WITH SCHIFF BASE DERIVED FROM 2-AMINO BENZOIC ACID AND SALICYLALDEHYDE
}

\author{
* Aliyu, H. N. and Ado, I. \\ Department of Chemistry Bayero University, P. M. B. 3011, Kano, Nigeria \\ Correspondence author: hnuhu2000@yahoo.com
}

\begin{abstract}
The complexes of Mn (II) and Ni (II) with Schiff base derived from salicylaldehyde and 2aminobenzoic acid have been prepared and characterized by gravimetry, potentiometry, molar conductance and infrared analyses. The solubility test on the Schiff base and its nickel(II) complex revealed their solubility in most organic solvents except ether, acetonitrile and tetrachloromethane. However, manganese(II) complex is insoluble in most organic solvents but soluble in dimethylsulphoxide (DMSO). The molar conductance of the complexes measured are, indicating their non-electrolytic nature. The potentiometric and spectrophotometric studies of the complex compounds revealed 1:1 metal to ligand ratio.
\end{abstract}

Keywords: Schiff base, azomethine, salicylaldehyde, potentiometry, spectrophotometry, 2-amino benzoic acid

\section{INTRODUCTION}

A Schiff base is a compound formed from the condensation of either an aldehyde or a ketone (Holm et al., 1966; Hobday and Smith, 1972; Pierre, 1987). The carbonyl group of the aldehyde gives aldimines while that of ketone gives ketoimines. It has been known that different metal ions on interaction with Schiff bases yield chelates, for example Tsumaki, (1983) reported [Co(sal 2 -en) Complex which received a great attention owing to its ability to undergo reversible adduct formation with molecular oxygen. The oxygenation ability of the complex was first recognized by Hassan (1998). However, the mechanism for the oxygenation process was not well understood until recently with the advent of modern physical techniques. Xishi et al. (2003), reported the synthesis and characterization of a novel Schiff base ligand formed from the condensation of 2,2-bis (Pmethoxyphenylamine) and Salicylaldehyde and its $\mathrm{Mn}(\mathrm{II}), \mathrm{Co}(\mathrm{II})$ and $\mathrm{Cu}(\mathrm{II})$ complexes. Then Ben Saber et al. (2005), reported the synthesis and characterization of $\mathrm{Cr}(\mathrm{III}), \mathrm{Fe}(\mathrm{III}), \mathrm{Co}(\mathrm{II})$ and $\mathrm{Ni}(\mathrm{II})$ complexes with a Schiff base derived from 4dimetylamino benzaldehyde and primary amines. The chemical analysis data showed the formation of $(1: 1)$ metal - ligand ratio and a square planar geometry was suggested for $\mathrm{Co}(\mathrm{II})$ and $\mathrm{Ni}$ (II) complex while an octahedral structure was suggested for $\operatorname{Cr}(I I I)$ and $\mathrm{Fe}(\mathrm{III})$ complexes. Ben Saber et al. (2005), reported the synthesis of a Schiff base derived from salicylaldeyde, and Histidine and its complex compounds with divalent transition metal ions. The complexes were investigated by elemental analysis and were found to be of 1:1 metal to ligand ratio.

Transition metal Schiff base complexes are used in various fields, such as medicine, agriculture, industries etc. For example, $\left[\mathrm{Co}\left(\mathrm{aCac}_{2}-\mathrm{en}\right)\right]$ in dimethylformamide, pyridine and substituted pyridines proved to be involved in oxygen metabolism (Hanna and Mona, 2001). Transition metal complexes with 1 , 10 - phenanthroline and 2, 2 - bipyridine are used in petroleum refining (John et al, 1976). Schiff base formed by the condensation of 1-formyl-2-hydry-3naphtholic arylamide with 0-hydroxyl or 0-methoxy aniline complexes of $\mathrm{Co}(\mathrm{II}), \mathrm{Ni}(\mathrm{II}), \mathrm{Cu}(\mathrm{II})$ and $\mathrm{Zn}(\mathrm{II})$ are useful as figments (Gupta et al, 2002). Oxovanadium Complexes have been found strongly active, against some type of Leukemia (Dong et al, 2002). Transition metal complexes derived from a number of amino acids have been reported to have biological activity (Zahid et al., 2007). Morad et al., (2007), reported the antibacterial activity of $\mathrm{Ni}(\mathrm{II})$ with salicyaldehyde and 2-amino-benzoic acid complex. Popova and Berova, (1981) reported that copper is good for liver function, its level in blood and urine has influence in pregnancy disorders, nephritis hepatitis, leprosy, anemia and leukemia in children. This paper reports the studies of manganese (II) and nickel (II) complexes of Schiff base derived from 2amino benzoic acid and salicylaldehyde due to paucity of information.

\section{MATERIALS AND METHODS}

Chemicals of analytical grade purity were used. Melting point and decomposition temperature were determined on Gallenkamp melting point apparatus. IR spectra measurements were recorded using Fourier Transformed IR Genesis series model in Nujol in the region $40000-400 \mathrm{~cm}^{-1}$. electrical conductivity measurements were carried out using conductivity meter model 4010. UV-visible spectral measurements were done on a Pye Unicam UV-visible spectrophotometer. 


\section{Preparation of the Schiff base}

The Schiff based formed from salicylaldehyde and 2amino benzoic acid was prepared by adding $25 \mathrm{~cm}^{3}$ of salicylaldehyde ethanolic solution $(1.22 \mathrm{~g}, 0.01 \mathrm{~mol})$ to the same volume of ethanolic solution of 2-amino benzoic acid $(1.37 \mathrm{~g}, 0.01 \mathrm{~mol})$. The mixture was refluxed for two hours. The product that formed was collected by filtration, washed several times with ethanol and recrystallized from hot ethanol. The orange colour product was then dried in dissicator over phosphorous pentoxide (EL-Ajialy et al., 2006).

\section{Preparation of Schiff base metal complexes}

The metal complexes were prepared by adding $25 \mathrm{~cm}^{3}$ of ethanolic solution of metal chloride $(0.01$ mole) with ethanolic solutions of the prepared Schiff base ( 0.01 mole) followed by drop wise addition of aqueous ammonia. The resulting mixture was refluxed for two hours and the metal complex compounds that precipitated out were filtered and then washed repeatedly with hot ethanol until the washing was colourless. The product was air dried over phosphorus pentoxide. (El-Ajaily, 2006).

\section{Determination of Dissociation Constant of Schiff Base}

To a $400 \mathrm{~cm}^{3}$ beaker were added $90 \mathrm{~cm}^{3}$ of distilled water, $100 \mathrm{~cm}^{3}$ of $0.2 \mathrm{M} \mathrm{KNO}_{3}, 10 \mathrm{~cm}^{3}$ of $0.4 \mathrm{M}$ Schiff base and a magnetic stirring bar before the electrodes of a standardized meter were introduced. A $10 \mathrm{~cm}^{3}$ of standardized aqueous $\mathrm{NaOH}$ was added dropwise with stirring. After each $0.5 \mathrm{~cm}^{3}$ addition, the amount of $\mathrm{NaOH}$ solution and the corresponding $\mathrm{pH}$ were recorded. Points in the 20 to 80 percent titration range were used to calculate the pKa (Gregory et al., 1978).

\section{Determination of Stability Constant of Complexes}

Into a $400 \mathrm{~cm}^{3}$ beaker $100 \mathrm{~cm}^{3}$ of $0.2 \mathrm{M} \mathrm{KNO}_{3}, 1 \mathrm{mmole}$ of metal (II) chloride, $0.1 \mathrm{M} \mathrm{HNO}_{3}$ and $90 \mathrm{~cm}^{3}$ of distilled water were added, respectively. A magnetic stirring bar and sodium salt of the Schiff base, prepared by neutralizing a known quantity of the Schiff base with calculated amount of standardized $\mathrm{NaOH}$ solution. After each $0.2 \mathrm{~cm}^{3}$ aliquot addition, the corresponding $\mathrm{pH}$ of the stirred reaction mixture was recorded. From the results obtained, stability constant of the complex compound and the number of the coordinated ligands per metal ion were determined (Gregory, et al 1978).

\section{RESULTS AND DISCUSSION}

The ligand prepared is crystalline orange, it is soluble in common organic solvents but insoluble in water. The manganese (II) and nickel (II) Schiff base complexes prepared are crystalline brown and have decomposition temperatures $206^{\circ} \mathrm{C}$ and $245^{\circ} \mathrm{C}$, respectively. These high decomposition temperatures revealed the stability of the complex compounds (Table 1), which is common with such complexes. The solubility tests carried out on the ligand and its nickel(II) complex showed that they are soluble in most common organic solvents but insoluble in water, indicating that the compounds are not ionic. However, the manganese(II) schiff base complex is insoluble in such solvents except dimethyl sulphoxide (Table 2). The molar conductance measurements of the complexes in $10^{-3} \mathrm{M}$ dimethylsulphoxide is in the range $17.39-18.12 \mathrm{~cm}^{2} \mathrm{ohm}^{-1} \mathrm{~mol}^{-1}$, which are relatively low, indicating their non-electrolytic nature (Table 3). The IR spectral data of the ligand showed a band at $1619 \mathrm{~cm}^{-1}$, which is assigned to $\left.\mathrm{VC}=\mathrm{N}\right)$ stretching vibration, a feature found in Schiff bases (J ezowska et al, 1988). This band is also observable in the complex compounds, suggesting that the ligand is coordinated to the respective metal ions, resulting in the formation of the two complexes (Prabhu and Dodwad, 1986). The bands in the regions $511-556 \mathrm{~cm}^{-1}$ and 450 $485 \mathrm{~cm}^{-1}$ are attributed to $\quad(M-O)$ and $V(M-N)$ stretching vibrations respectively, confirming the coordination of the Schiff base to the respective metal ions. The broad band in the region $3350-3560 \mathrm{~cm}^{-1}$ is accorded to $(\mathrm{O}-\mathrm{H})$ stretching vibrations, a feature indicating the presence of water (Table 4). The water analysis of the complexes suggested two water molecules per complex compound. According to a similar work by Morad et al. (2007), one of the two water molecules is coordinated to the metal ion, and the other is water of hydration. The dissociation constant (pKa) of the Schiff base is 5.95, suggesting weak acid (Table 5). The stability constants of Mn (II) and $\mathrm{Ni}$ (II) Schiff base complexes are $1.0 \times 10^{13}$ and $3.98 \times 10^{14}$, respectively, indicating reasonable stability of the complexes, supported by high decomposition temperatures shown in Table 1. The potentiometric studies also suggested 1:1 metal - ligand ratio for the manganese (II) and nickel (II) complexes, respectively (Tables 6 and 7).

From the analyses of the complexes the general molecular structure has been proposed below:

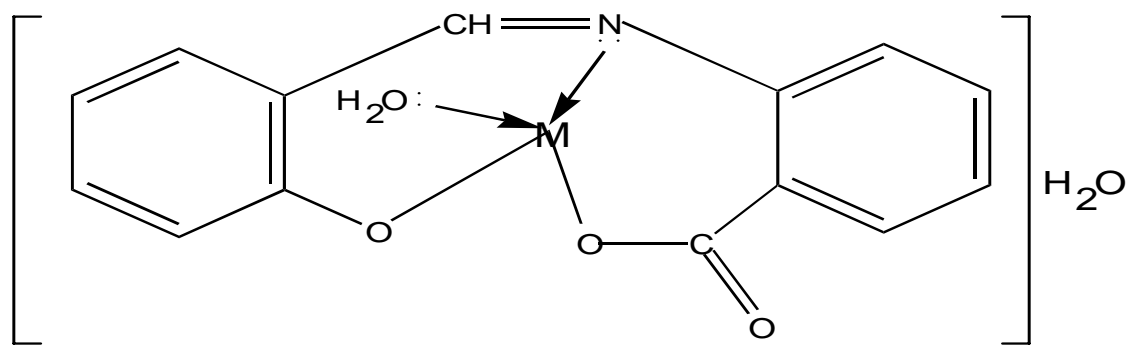

Fig. 1: The molecular structure of the complexes, where $\mathrm{M}$ is $\mathrm{Mn}(\mathrm{II})$ or $\mathrm{Ni}(\mathrm{II})$ 
Bajopas Volume 3 Number 1 June 2010

Table 1: The percentage yield, colour, decomposition temperature of the compounds

Compound Colour \% yield

Decomposition Temp

$\left({ }^{\circ} \mathrm{C}\right)$

\begin{tabular}{llll}
{$\left[\mathrm{MnLH}_{2} \mathrm{O}\right] \mathrm{H}_{2} \mathrm{O}$} & Pale brown & 61.50 & 206 \\
{$\left[\mathrm{NiLH}_{2} \mathrm{O}\right] \mathrm{H}_{2} \mathrm{O}$} & Pale brown & 83.64 & 215 \\
\hline
\end{tabular}

Table 2: The Solubility of the compounds in some common organic solvents.

Compound Water Methanol Ethanol Acetone DMSO Ether Acetonitrile Nitrobenzene Tetrachloro

methene

\begin{tabular}{llcccccccc}
\hline $\mathrm{MnL}\left[\mathrm{H}_{2} \mathrm{O}\right] \mathrm{H}_{2} \mathrm{O}$ & IS & $\mathrm{S}$ & $\mathrm{S}$ & $\mathrm{S}$ & $\mathrm{S}$ & IS & IS & S & IS \\
$\left.\mathrm{NiL}_{2} \mathrm{H}_{2} \mathrm{O}\right] \mathrm{H}_{2} \mathrm{O}$ & IS & IS & IS & IS & S & IS & IS & IS & IS \\
\hline
\end{tabular}

Key: IS = insoluble, $\mathrm{S}=$ soluble

Table 3: The molar conductivity measurements of the compounds in $10^{-3} \mathrm{M}$ DMSO

\begin{tabular}{|c|c|c|c|}
\hline Complex & Concentration moldm ${ }^{-3}$ & $\begin{array}{l}\text { Specific Conductance } \\
\left(\mathrm{Ohm}^{-1} \mathrm{~cm}^{2}\right)\end{array}$ & $\begin{array}{l}\text { Molar conductance } \\
\left(\mathrm{Ohm}^{-1} \mathrm{Sm}^{2} \mathrm{~mol}^{-1}\right)\end{array}$ \\
\hline$\left[\mathrm{MnL} \mathrm{H}_{2} \mathrm{O}\right] \mathrm{H}_{2} \mathrm{O}$ & $\begin{array}{l}1.0 \times 10^{-3} \\
1.0 \times 10^{-3}\end{array}$ & $\begin{array}{l}18.12 \times 10^{-6} \\
17.39 \times 10^{-6}\end{array}$ & $\begin{array}{l}18.12 \\
17.39\end{array}$ \\
\hline
\end{tabular}

Table 4: The IR spectra of the Schiff base and the complexes

\begin{tabular}{|c|c|c|c|c|}
\hline Compound & $V(C=N)\left(\mathrm{cm}^{-1}\right)$ & $V(0-\mathrm{H})\left(\mathrm{cm}^{-1}\right)$ & $V(\mathrm{M}-0)\left(\mathrm{cm}^{-1}\right)$ & $V(\mathrm{M}-\mathrm{N})\left(\mathrm{cm}^{-1}\right)$ \\
\hline Schiff base & 1619 & $3350-3560$ & - & - \\
\hline$\left(\mathrm{MnL} \mathrm{H}_{2} \mathrm{O}\right] \mathrm{H}_{2} \mathrm{O}$ & 1620 & $3360-3570$ & $511-556$ & $450-485$ \\
\hline$\left[\mathrm{NiL} \mathrm{H}_{2} \mathrm{O}\right] \mathrm{H}_{2} \mathrm{O}$ & 1618 & $3355-3560$ & $520-560$ & $440-470$ \\
\hline
\end{tabular}

Table 5: The dissociation constant (pKa) of the Schiff base

\begin{tabular}{|c|c|c|c|c|c|c|}
\hline $\mathbf{S} / \mathbf{N}$ & $\begin{array}{l}\text { Vol. of } \mathrm{NaOH} \\
\left(\mathrm{Cm}^{3}\right)\end{array}$ & pH & {$\left[\mathrm{Na}^{+}\right] \times 10^{-3}$} & {$\left[\mathrm{H}^{+}\right] \times 10^{-5}$} & {$[\mathrm{OH}] \times 10^{-10}$} & pKa \\
\hline 1. & 0.5 & 3.66 & 1.22 & 29.2 & 62.3 & 4.36 \\
\hline 2. & 1.0 & 3.94 & 2.44 & 7.68 & 1.22 & 4.96 \\
\hline 3. & 1.5 & 4.17 & 4.86 & 3.35 & 2.93 & 4.97 \\
\hline 4. & 2.0 & 4.30 & 5.65 & 4.52 & 2.32 & 4.99 \\
\hline 5. & 2.5 & 4.48 & 6.05 & 2.22 & 5.30 & 5.01 \\
\hline 6. & 3.0 & 4.68 & 7.24 & 1.32 & 8.03 & 5.12 \\
\hline 7. & 3.5 & 4.84 & 8.24 & 0.583 & 0.184 & 5.25 \\
\hline 8. & 4.0 & 5.06 & 8.43 & 0.583 & 0.184 & 5.25 \\
\hline 9. & 4.5 & 5.35 & 9.61 & 0.299 & 0.305 & 5.52 \\
\hline 10. & 5.0 & 5.93 & 10.8 & 0.0786 & 0.595 & 5.90 \\
\hline
\end{tabular}

Table 6: Determination of the number of coordinated Schiff base per manganese (II) ion

\begin{tabular}{|c|c|c|c|c|c|c|}
\hline $\mathbf{S} / \mathbf{N}$ & $\begin{array}{l}\text { Vol. } \\
\text { NaOH } \\
\left(\mathrm{Cm}^{3}\right)\end{array}$ & of $\mathrm{pH}$ & {$\left[\mathrm{H}^{+}\right] \times 10^{-3}$} & {$\left[\mathrm{OH}^{-}\right] \times 10^{-11}$} & $\dot{\mathbf{N}}$ & $\log \left[A^{-}\right]$ \\
\hline 1 & 2.2 & 2.31 & 3.35 & 0.48 & 0.5 & -8.55 \\
\hline 2 & 2.4 & 2.33 & 3.13 & 0.52 & 0.5 & -8.25 \\
\hline 3 & 2.6 & 2.35 & 2.99 & 0.57 & 0.7 & -7.82 \\
\hline 4 & 2.8 & 2.37 & 2.85 & 0.57 & 0.7 & -7.82 \\
\hline 5 & 3.0 & 2.40 & 2.66 & 0.61 & 0.7 & -7.69 \\
\hline 6 & 3.2 & 2.42 & 2.54 & 0.64 & 0.8 & -7.58 \\
\hline 7 & 3.4 & 2.43 & 2.48 & 0.66 & 0.8 & -7.47 \\
\hline 8 & 3.6 & 2.45 & 2.37 & 0.68 & 0.9 & -7.37 \\
\hline 9 & 3.8 & 2.48 & 2.22 & 0.73 & 0.9 & -7.28 \\
\hline 10 & 4.0 & 2.50 & 2.12 & 0.77 & 1.0 & -7.16 \\
\hline 11 & 4.2 & 2.52 & 2.02 & 0.80 & 1.0 & -7.05 \\
\hline 12 & 4.4 & 2.55 & 1.89 & 0.86 & 1.1 & -7.02 \\
\hline 13 & 4.6 & 2.57 & 1.80 & 0.90 & 1.1 & -6.85 \\
\hline 14 & 4.8 & 2.59 & 1.72 & 0.94 & 1.2 & -6.74 \\
\hline 15 & 5.0 & 2.60 & 1.68 & 1.30 & 1.3 & -6.65 \\
\hline 16 & 5.2 & 2.63 & 1.57 & 1.03 & 1.4 & -6.53 \\
\hline 17 & 5.4 & 2.65 & 1.50 & 1.08 & 1.4 & -6.53 \\
\hline 18 & 5.6 & 2.66 & 1.43 & 1.11 & 1.5 & -6.35 \\
\hline 19 & 5.8 & 2.69 & 1.37 & 1.19 & 1.6 & -6.25 \\
\hline 20 & 6.0 & 2.71 & 1.31 & 1.24 & 1.6 & -6.20 \\
\hline
\end{tabular}




\begin{tabular}{|c|c|c|c|c|c|c|}
\hline $\mathbf{S} / \mathbf{N}$ & $\begin{array}{l}\text { Vol. of } \\
\text { NaOH } \\
\text { (Cm3) }\end{array}$ & pH & {$[\mathrm{H}+] \times 10-3$} & $\begin{array}{c}{[\mathrm{OH}-] \times 10-} \\
11\end{array}$ & Ň & $\log [A-]$ \\
\hline 21 & 6.2 & 2.73 & 1.25 & 1.03 & 1.7 & -6.18 \\
\hline 22 & 6.4 & 2.76 & 1.16 & 1.40 & 1.8 & -6.14 \\
\hline 23 & 6.6 & 2.78 & 1.11 & 1.46 & 1.8 & -5.76 \\
\hline 24 & 6.8 & 2.81 & 1.04 & 1.57 & 1.9 & -6.06 \\
\hline 25 & 7.0 & 2.83 & 0.99 & 1.64 & 2.0 & -6.03 \\
\hline 26 & 7.2 & 2.85 & 0.95 & 1.72 & 2.0 & -6.00 \\
\hline 27 & 7.4 & 2.87 & 0.90 & 1.80 & 2.1 & -5.97 \\
\hline 28 & 7.6 & 2.90 & 0.84 & 1.93 & 2.2 & -5.97 \\
\hline 29 & 7.8 & 2.92 & 0.81 & 2.02 & 2.2 & -5.96 \\
\hline 30 & 8.0 & 2.94 & 0.77 & 2.11 & 2.3 & -5.96 \\
\hline
\end{tabular}

Average $\tilde{n}=1.36$

Table 7: Determination of the number of coordinated Schiff base per nickel (II) ion

\begin{tabular}{|c|c|c|c|c|c|c|}
\hline $\mathbf{S} / \mathbf{N}$ & $\begin{array}{l}\text { Vol. of } \mathrm{NaOH} \\
\left(\mathrm{Cm}^{3}\right)\end{array}$ & pH & {$\left[\mathrm{H}^{+}\right] \times 10^{-3}$} & {$\left[\mathrm{OH}^{-}\right] \times 10^{-12}$} & $\tilde{\mathbf{N}}$ & $\log \left(A^{-}\right)$ \\
\hline 1. & 2.2 & 2.27 & 3.58 & 4.51 & 0.6 & -9.61 \\
\hline 2. & 2.4 & 2.29 & 3.43 & 4.73 & 0.6 & -9.42 \\
\hline 3. & 2.6 & 2.31 & 3.28 & 4.95 & 0.7 & -8.28 \\
\hline 4. & 2.8 & 2.32 & 3.20 & 5. & 0.7 & -9.17 \\
\hline 5. & 3.0 & 2.34 & 3.06 & 5.30 & 0.8 & -9.05 \\
\hline 6. & 3.2 & 2.35 & 2.99 & 5.43 & 0.8 & -8.88 \\
\hline 7. & 3.4 & 2.37 & 2.85 & 5.68 & 0.9 & -8.91 \\
\hline 8. & 3.6 & 2.39 & 2.73 & 5.95 & 0.9 & -8.83 \\
\hline 9. & 3.8 & 2.41 & 2.60 & 6.23 & 1.0 & -8.77 \\
\hline 10. & 4.0 & 2.43 & 2.49 & 6.52 & 1.0 & -8.71 \\
\hline 11. & 4.2 & 2.45 & 2.37 & 6.83 & 1.1 & -8.60 \\
\hline 12. & 4.4 & 2.46 & 2.32 & 6.99 & 1.1 & -8.54 \\
\hline 13. & 4.6 & 2.48 & 2.22 & 7.32 & 1.2 & -8.49 \\
\hline 14. & 4.8 & 2.49 & 2.17 & 7.49 & 1.2 & -8.41 \\
\hline 15. & 5.0 & 2.51 & 2.07 & 7.84 & 1.3 & -8.34 \\
\hline 16. & 5.2 & 2.53 & 1.98 & 8.21 & 1.3 & -8.28 \\
\hline 17. & 5.4 & 2.55 & 1.89 & 8.60 & 1.4 & -8.19 \\
\hline 18. & 5.6 & 2.56 & 1.84 & 8.80 & 1.4 & -8.06 \\
\hline 19. & 5.8 & 2.58 & 1.76 & 9.22 & 1.5 & -7.94 \\
\hline 20. & 6.0 & 2.60 & 1.68 & 9.87 & 1.5 & -7.78 \\
\hline 21. & 6.2 & 2.63 & 1.57 & 10.3 & 1.6 & -7.42 \\
\hline 22. & 6.4 & 2.64 & 1.53 & 10.6 & 1.6 & -7.24 \\
\hline 23. & 6.6 & 2.66 & 1.46 & 11.1 & 1.7 & -7.10 \\
\hline 24. & 6.8 & 2.68 & 1.40 & 11.6 & 1.7 & -6.95 \\
\hline 25. & 7.0 & 2.71 & 1.31 & 12.4 & 1.8 & -7.73 \\
\hline 26. & 7.2 & 2.73 & 1.25 & 13.0 & 1.8 & -6.65 \\
\hline 27. & 7.4 & 2.76 & 1.16 & 14.0 & 1.9 & $-6 / 50$ \\
\hline 28. & 7.6 & 2.79 & 1.09 & 15.0 & 1.9 & -6.43 \\
\hline 29. & 7.8 & 2.82 & 1.01 & 16.0 & 2.0 & -6.36 \\
\hline 30. & 8.0 & 2.85 & 0.945 & 17.2 & 2.1 & -6.34 \\
\hline
\end{tabular}

Average number of coordinated ligands $(\tilde{n})=1.37$

\section{REFERENCES}

Ben Saber, S.M, Mailub A.A., Hudere S.S, and El-ajaily M.M (2005), complexation behavior of some Schiff base complexes toward transition metal ions. Micro chemical journal, 81, 191194.

Dong, Y; Narla, RK; Sudbeck, E; (2002) Synthesis, Xray structure, and anti-leukemic activity of oxovanadium (IV) complexes, journal of Inorganic Biochemistry Vol. 78, pp 321-330

El-ajaily, M.M. Maihub, A.A, Hudere S.S. and Ben Saber S. M. (2006) Nickle (II) chelate of Schiff base derived from 4-dimethyl-aminobenzaldehyde with systeine. Asian Journal of chemistry society, 18(4).2427-2430.

Gregory, S; Thomas, B.R, Robert, JA, (1978) "Synthesis and Techniques in Inorganic Chemistry" $3^{\text {rd }}$ edition, Longman pub., London pp 119-126. 
Gupta S.K. Hitchcock R.H and Kushwah Y.S. (2002), Synthesis, characterization and crystal structure of a $\mathrm{Ni}$ (ii) shiff base complex derived from acetylacetone and ethylene diamine; J. of coord. Chem...,55 (12), 14011407.

Hanna Wageih G., Moawaad Mona (2001). Synthesis, characterization and antimicrobial activity of $\mathrm{Co}$ (II), $\mathrm{Ni}$ (II) and $\mathrm{Cu}$ (II) with new asymmetrical Schiff base, transition metal chemistry 26(6), 644-651.

Hassan, A.M.A. (1998). Co (II) and Fe (III) chelates drived from Isatin and some amines Journal of I slamic academy sciences, 4(4), 271-274.

Hobday, M. D. and Smith, T. D., (1972); 'N, N'ethylene bis(salicylideneiminato) Transition Metal ion Chelates", Coordination Chemistry Review, 9: 311-337.

Holm, R. H., Everett, J. R., and Chakravorty, R. S., (1966); "Metal Complexes of Schiff Bases and $\beta$-ketoimines", Inorganic Chemistry, 7: 83214.

Jezowska, B. Lisowski, J. and Chemielewski P. (1988) synthesis and spectroscopic studies of Schiff base complexes polyhedron, 7(5), 337-340.

John, J. Alexander H. P. and Magret, J.S, (1976); Chemistry with Laboratory, Harcout Bruce, Johanovich, pp 63-64.
Morad, F.M. El-Ajaily, S. and Gweirif B. (2007). J. of science and its Appl. Vol. 1, pp 72-78.

Pierre, (1987), "Organic reactions", Johnson Wiley Pub. New York USA pp. 73-79.

Prabhu, PS and Dodwad S.S. (1986).studies on some Schiff base complexes. J. Indian of chem.,58, 478-482.

Popora, E. and Berova, S. (1981). "copper as coating for ceramies" Bulgarius chemical abstract vol. 84, pp 184.

Sonmez, M. and Sekerel, M. (2002). Synthesis and spectroscopic investigation of some Schiff base complexes. Pub. J. of chem., 76, 907914

Tsumaki T. (1983). Synthesis and characterization of bis(salicyl)ethylenediiminatocobalt(II) complex, Bull. Chem... soc. Jap, 13, 254.

Xishi, T., Xian, H. Y., Qiang, C. and Minyu, T., (2003), "Synthesis of Some Transition Metal Complexes of a Novel Schiff Base Ligand Derived from 2, 2' - Bis(p-Methoxy Phenylamine) and Salicylic Aldehyde", Molecules, 8: 439-443.

Zahid H. Chohan, Arif M., Akhtar A. and Claudiu T. Supuran (2007) Bioinorg chem... And Appl. Article 1D 83131, pp 1-13. 